\title{
A geographical information system for the management of the aquaculture data in the Adriatic Sea - the Strengthening of Centres for Aquaculture Production and Safety surveillance in the Adriatic countries experience: Present capabilities, tools and functions
}

\author{
Susanna Tora, ${ }^{1}$ Silvio Sacchini, ${ }^{1}$ Eddy Listeš, ${ }^{2}$ Tanja Bogdanović, ${ }^{2}$ Alessio Di Lorenzo, ${ }^{1}$ \\ Muhamed Smajlović, ${ }^{3}$ Ahmed Smajlović, ${ }^{4}$ Jelena V. Filipović, ${ }^{5}$ Vildana Tahirović, ${ }^{6}$ \\ Danijela Šuković, ${ }^{7}$ Bojan Beljkas, ${ }^{7}$ Ardian Xinxo, ${ }^{8}$ Renis Maçi, ${ }^{8}$ Patrizia Colangeli, ${ }^{1}$ \\ Federica Di Giacinto, ${ }^{1}$ Annamaria Conte ${ }^{1}$
}

\begin{abstract}
${ }^{1}$ Istituto Zooprofilattico Sperimentale dell'Abruzzo e del Molise G. Caporale, Teramo, Italy; ${ }^{2}$ Croatian Veterinary Institute, Regional Veterinary Institute Split, Split, Croatia; ${ }^{3}$ Department of Food Safety and Technology, Veterinary Faculty, University of Sarajevo, Sarajevo; ${ }^{4}$ Department of Pharmacology and Toxicology, Veterinary Faculty, University of Sarajevo, Sarajevo, Bosnia and Herzegovina; ${ }^{5}$ Ministry of Agriculture and Rural Development, Administration for Food Safety, Veterinary and Phytosanitary Affairs, Podgorica, Montenegro; ${ }^{6}$ Ministry of Foreign Trade and Economic Relation, Veterinary Office of Bosnia and Herzegovina, Sarajevo, Bosnia and Herzegovina; ${ }^{7}$ Center for Eco-Toxicological Research, PodgoricaCETI, Podgorica, Montenegro; ${ }^{8}$ Food Safety and Veterinary Institute, Tirana, Albania
\end{abstract} Correspondence: Susanna Tora, Istituto Zooprofilattico Sperimentale
dell'Abruzzo e del Molise G. Caporale, Campo Boario, 64100 Teramo, Italy.
Tel: +39.0861 .332249 .

E-mail: s.tora@izs.it

Key words: Web GIS; Information system; Adriatic Sea; Surveillance plans; Contaminants.

Acknowledgments: this work was supported and funded by IPA Adriatic Cross-Border Cooperation Programme 2007-2013 (http://www.ipadriaticbc.eu/).

Contributions: ST designed and developed the Information System and the Web GIS, and wrote the manuscript. SS designed and developed the Information System and the Web GIS and contributed to write the first draft of the manuscript. ADL contributed to design and develop the Information System and the Web GIS and contributed to write the first draft of the manuscript. EL, TB, MS, AS, JVF, VT, DŠ, BB, AX, RM, $\mathrm{PC}, \mathrm{FDG}$, contributed to the design of the Information System and helped in drafting the manuscript. AC designed the Information System and the Web GIS, contributed to its development, and wrote the manuscript. All authors reviewed the manuscript and contributed to the final submission. All authors read and approved the final manuscript.

Conflict of interest: the authors declare no potential conflict of interest.

Received for publication: 8 June 2017.

Revision received: 23 August 2017.

Accepted for publication: 1 September 2017.

(C) Copyright S. Tora et al., 2017

Licensee PAGEPress, Italy

Geospatial Health 2017; 12:593

doi:10.4081/gh.2017.593

This article is distributed under the terms of the Creative Commons Attribution Noncommercial License (CC BY-NC 4.0) which permits any noncommercial use, distribution, and reproduction in any medium, provided the original author(s) and source are credited.

\section{Abstract}

The European Commission (EC) regulation no. 854/2004 requires a systematic monitoring of chemical and microbiological contaminants in live bivalve molluscs, live echinoderms, live tunicates and live marine gastropods for human consumption through surveillance plans to be implemented in all European Union (EU) countries. A consortium of five Adriatic countries was set up in the framework of the Instrument of Pre-accession Assistance Adriatic Cross-border Cooperation Programme (IPA Adriatic CBC) 2007 2013 with the aim of collecting data and distribute information on harvesting and production in mollusc areas. A web-based geographical information system (GIS) application was developed to support the partners to manage data and to make these data available to final users, policy makers and to risk assessors. The GIS for the Strengthening of Centres for Aquaculture Production and Safety surveillance in the Adriatic countries (CAPS2) is divided into two levels, the national and the supranational one, and it distributes spatial and epidemiological information coming from various data acquisition and management sites. The great innovation is the possibility for each country to use online drawing, modifying and change of the geographic areas according to national surveillance needs. Currently it hosts data coming from about 230 production and relay areas with more than 29,478 laboratory tests performed on collected samples since August 2014. Data collected are used by each national competent authority to classify production or relay areas according to the EC regulation mentioned and to conduct risk assessment studies to evaluate the level of consumers' exposure to contaminants in the consumption of bivalve mollusc products.

\section{Introduction}

The fishery sector is one of the most strategic for the economies of the Adriatic cross-border countries. The more than 
one thousand $\mathrm{km}$ of coast belonging to these countries represent an extraordinary resource not only for the tourist sector, but also for the production of high-quality fishery and shellfish products, which are increasingly present in the diet of consumers due to high percentage of polyunsaturated fatty acids, fat-soluble vitamins, high protein content, low cholesterol and high content of essential elements (Grigorakis, 2007). Production and trade in this sector is increasingly important in the Adriatic area and the attention paid to the quality and safety of fishery products and shellfish is growing both at the national and the European level. According to national regulations and directives by the European Union (EU) and the European Parliament Council of the EU (EPCEU) the laboratories operating in the Adriatic countries should be well prepared to meet the surveillance needs in terms of potential chemical, microbiological and toxicological contamination. Current EU legislation is focused on measures maintaining a clean and healthy marine environment, i.e., contaminants in fish and other seafood for human consumption must not exceed concentrations established in regulations and directives (European Commission, 2006, 2011, 2013; EPCEU, 2004a, 2008). A large number of EU countries have organised systematic monitoring of potential contamination of bivalve mollusc, live echinoderms, live tunicates and live marine gastropods (in following text referred to as bivalve molluses for short) based on these directives. These molluscs are widely used in coastal monitoring programmes and pollution assessment studies as they are sessile organisms with a worldwide geographical distribution. They are filter-feeders with a slow rate of detoxification and they have an ability to accumulate many different toxic contaminants (Bogdanović et al., 2014; Ujević et al., 2015). EC regulation 854/2004 and directives issued by the EPCEU (EPCEU, 2004b) on 29 April 2004 stipulate specific rules for the organisation of official controls on products of animal origin intended for human consumption. In particular, competent authorities (CA) must decide on the location and the geographic boundaries of production areas for bivalve molluscs. The production areas from which harvesting is authorised are divided into three classes: class A) areas from which molluscs may be collected for direct human consumption; class B) areas from which molluscs may be collected but placed on the market for human consumption only after treatment in a purification centre or after relaying; and class C) areas from which molluscs may be collected but placed on the market only after relaying over a long period (at least two months) or after heat treatment by an approved method. In order to enable production areas to be classified, the CA must establish a sampling programme to verify the microbiological quality of all bivalve molluscs offered for sale and check for the presence of toxin-producing plankton and chemical contaminants. In this scenario, a consortium, consisting of Italy, Croatia, Montenegro, Albania and Bosnia-Herzegovina, established a strengthening programme with respect to the surveillance of seafood contaminations in the Adriatic area and created a platform to share epidemiological information related to the areas investigated. A real-time information system and a Web-based GIS application were developed to support the consortium to manage data collected during surveillance and monitoring activities and to make these data available to final users as well as policy makers and risk assessors. In this context, the CA were provided with operational tools to establish and keep a number of approved production and relay areas up to date according to the EC regulation 854/2004.

The aim of the paper is to describe in detail the technological capabilities, tools and function of the information system and the
Web-based GIS application currently operational in the Adriatic countries. Classification of production and relay areas is also provided for each country. An extended risk assessment of the entire Adriatic area will be developed in the future in accordance with all participating countries.

\section{Materials and Methods}

\section{System architecture}

The CAPS2 GIS was developed to manage data and information both at national and supranational levels. Data coming from the national surveillance plans in place in each country are managed at the national level and these data are exclusively accessible by in-country users. The supranational Web GIS provides geospatial tools visualising the classification of production areas and sampling sites of the entire Adriatic area of interest and gives access to this information at both public and restricted levels.

At the national level, users can access their country's public server which hosts database storage for both spatial and general epidemiological data (see the Italian example in Figure 1A). At the supranational level, each country's data are shared as Web services with a central server located in Italy that distributes data in the form of maps and tables through the Web GIS and the information system (Figure 1B). Figure 1 as a whole reports the schematic representation of the two levels discussed here.

\section{Data collection}

Two sets of data populate the database: spatial and general, epidemiological data. The former represent the production or relay areas and sampling sites (using polygon and point geometries directly inserted by the users). The spatial reference system adopt-

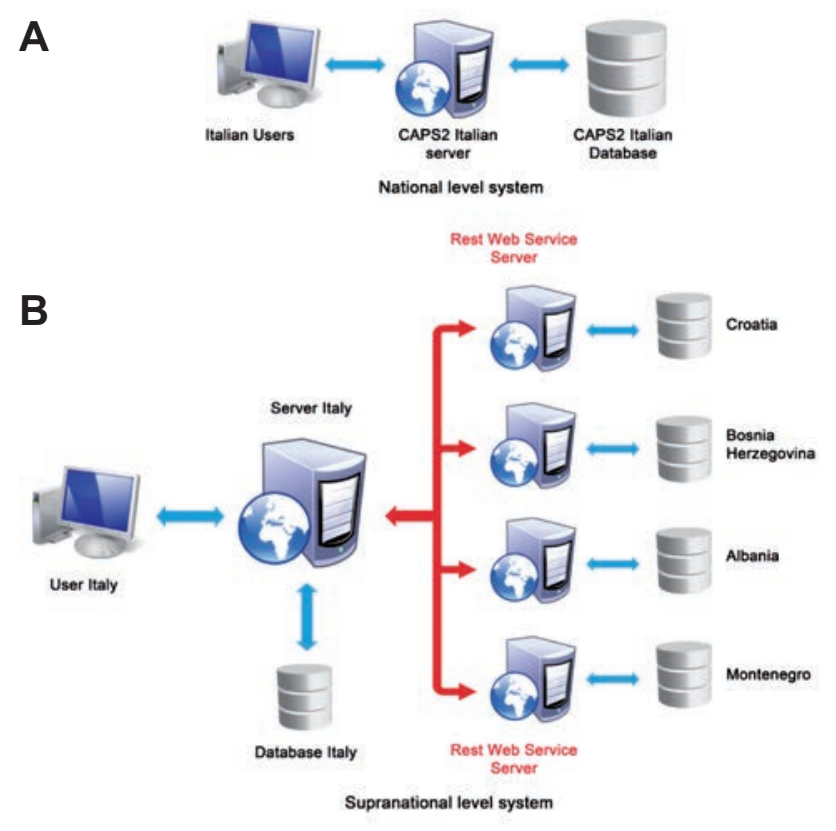

Figure 1. National and supranational level systems. A) Italian system as an example; B) architecture at the supranational level. 
ed is the geographic coordinate system (GCS) world geodetic system (WGS) of 1984 (WGS 84), which is the established standard CGS for use in cartography, geodesy and navigation.

Pure spatial data come from the monitoring and surveillance plans in place in each country. The attributes linked to the areas are: code, area name, start date of validity and category (i.e., production area, preliminary production area, harvesting area, farm or undefined area). The sampling sites contain the point name and mandatory information related to the production area or the relay area they belong to.

The epidemiological data are collected by veterinary services and laboratories and can be grouped as follows: sampling data (sample code, date of collection, water temperature, water salinity, test to be performed, materials and species); test results (contamination level, presence/absence, unit of measurement, test laboratory date); and classification containing the information about the health status of the production or relay areas including start date of validity and an open or closed state. The class categories are defined according to the EC regulation 854/2004 with an added class D that stands for restricted/unacceptable.

The base maps shown in CAPS2 GIS are provided by Mapbox and Google Maps as tiled maps services (TMS).

\section{Application modules and data flow}

\section{The national level}

This level consists of a set of Web-based data management GIS applications, such as user, sampling, test result, geographical unit (area management and point management), classification and database. The user Web application manages users and profiles according to privileges and requests. Table 1 summarises the actions that are allowed (or not allowed) for each profile.

The sampling application manages sample collection and delivery to the laboratory through a guided input form and provides users with tools and filters to search for the records of a specific sample, while test result manages the outcome of analyses performed. It is used for entering test values and tools and filters are available to search for specific samples along with the recorded results for each sample, which can all be downloaded as an Excel spreadsheet. The geographical unit menu, the real innovation of the system, was developed to create, edit or delete production or relay areas and the associated sampling points. The application has an interactive map capable of showing areas and points, and a table showing the list of the geographical units already recorded in the GIS. Map navigation tools and data filters are available on the toolbar at the top. It is possible to add/edit a production or relay area or a sampling point by entering the coordinates or drawing directly on the map using the mouse. The classification application is used to add or modify the health classification of the production or relay areas. This application is composed by an interactive map that displays the classification of these areas and a table with additional information (the health status history). It is also possible to load a regulation document that establishes the classification of the areas as a PDF attachment (maximum $5 \mathrm{MB}$ ). The classification application includes navigation tools, data filters and a legend describing the classification of each area, while the database manages lists of materials, species, contaminants and units of measure that system administrators can integrate or modify according to their own needs.

\section{The supranational level}

This level has both a public and restricted access. The former allows the visualisation of the health status of the production or relay areas according to EC regulation 854/2004, while the sampling points are only shown in terms of geographical location. The restricted access displays information about results from the sampling points (positive, negative, etc.) together with the health status of the production or relay areas. Only registered users can access this detailed information and they can only do it with reference to their own country. Tools for map navigation and data selection are available both for public and restricted access. The legend explains the symbols for the production areas, the relay areas and the sampling points. It is also possible to filter the data displayed on the map by applying filter criteria, such as year, country, category, area and points.

\section{Data flow}

The correct way to enter new data (spatial and epidemiological) is displayed in Figure 2. The first step is to create the geographical unit (a polygon representing a production/relay area or a point representing a sampling site); then it is possible to link the field sampling to the area/point recording all the information of the sampling. Once the sample is processed in laboratory for microbiological or chemical contaminants, results can be entered into the system based on the results obtained and the CA can classify the area according to regulation requirements. When data have been updated in the national-level database, they are automatically displayed in the supranational Web GIS application.

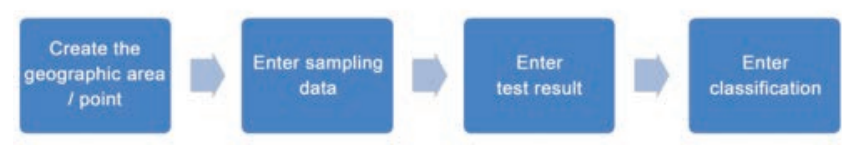

Figure 2. Data flow in the web applications at the national level.

Table 1. Access organisation.

\begin{tabular}{|c|c|c|c|c|c|c|}
\hline \multirow[t]{2}{*}{ User profile } & \multicolumn{6}{|c|}{ Web GIS and Web applications } \\
\hline & User & Sampling & Test result & Geographical unit & Classification & Database \\
\hline Competent authority & $\bullet$ & $\bullet$ & $\bullet$ & $\checkmark$ & $\checkmark$ & $x$ \\
\hline System administrator & $\checkmark$ & $\bullet$ & $\bullet$ & $\checkmark$ & $\bullet$ & $\checkmark$ \\
\hline Laboratory & $x$ & $\checkmark$ & $\checkmark$ & $x$ & $x$ & $x$ \\
\hline Sampling operator & $x$ & $\checkmark$ & $\bullet$ & $x$ & $x$ & $x$ \\
\hline Guest & $x$ & $\bullet$ & $\bullet$ & $x$ & $x$ & $x$ \\
\hline
\end{tabular}

GIS, geographical information system. $\checkmark$, Enter and view data; $\bullet$, view data; $\boldsymbol{x}$, none of these. 


\section{Software}

The CAPS2 GIS was developed using both open-source and proprietary software. The software infrastructure is composed by Oracle 11g Express Edition (XE) database management system, a small-footprint database based on the Oracle $11 \mathrm{~g}$ code, which is free to download and simple to administer. In addition, a J2EE business logic layer and a number of client frameworks and libraries are needed.

The epidemiological and spatial data are stored in the Oracle XE $11 \mathrm{~g}$ database and shown as representational state transfer (RESTful) Web services available for client Web applications. Each request sent to the server uses parameters to build the appropriate structured query language (SQL), a domain-specific language used in programming. The Spring annotation-based Model View Controller (MVC) framework (https://docs.spring.io/ spring/docs/current/spring-framework-reference/html/mvc.html) simplifies the process of creating RESTful Web services, while the Web application implements Spring Security, a robust mechanism that provides a complete support for both authentication and authorisation and protection.

Passwords stored in the database are generated randomly by the system and encrypted with the MD5 encoding algorithm, a widely used message digest designed to be used as a cryptographic hash function. Once a password has been generated, it is sent to the user's email address to be used for the first log in. The generated passwords can be changed directly by the users at any moment.

The client Web applications available in the CAPS2 GIS was developed with the OpenLayers 2.13 .1 (https://openlayers.org/) and jqGrid 4.6.0 JavaScript libraries (http://www.trirand.com/ blog/). Twitter Bootstrap v3.0.3 (https:/getbootstrap.com/) and jQuery-UI (https://jqueryui.com/) were used to build the tools of the user interface of the CAPS2 GIS and to harmonise the style of the whole platform.
Each national level system shares its own data in the form of Web services available for the supranational application through a call sent by the national server in use (acting as proxy), which means that the data of interest are returned to the supranational level sending a query to the underlying national system level database when a Web service is invoked.

\section{Results}

The CAPS2 GIS is accessible using a common Web browser at http://www.caps2.eu/. Currently (access August 2017) the CAPS2 GIS hosts about 50 users from different countries and with different roles who manage data coming from about 230 production and relay mollusc areas (Table 2). Samplings have been performed since August 2014 and the amount of tests performed up to now is 29,478 (Table 2).

In Figure 3 the supranational Web GIS application shows the classification results for the entire Adriatic area and Table 3 reports the classification of the sampled areas for each country. When logging into the system, the worst laboratory data (with respect to contamination) at each sampling point of the user's country become visible as shown in Figure 4. The supranational level application displays all data registered at the national level for all participating countries. Detailed data on test results are available from the CA by request.

Figure 5 shows all available applications at the national level. Users authorised to upload sample information ranging from collection to delivery at the laboratory, can use the second Web application, i.e. sampling entering standard information required on a Web-generated form (Figure 6). Once the sample has been received at the laboratory and tested, the results can be uploaded

Table 2. Use of the system by currently participating countries.

\begin{tabular}{|c|c|c|c|c|c|c|c|}
\hline Country & Monitored areas (n) & & Test: & formed on collec & samples & & \\
\hline & & $\begin{array}{c}\text { Biotoxin } \\
\text { tests }\end{array}$ & $\begin{array}{l}\text { Chemical } \\
\text { tests }\end{array}$ & $\begin{array}{c}\text { Microbiological } \\
\text { tests }\end{array}$ & $\begin{array}{l}\text { Test for } \\
\text { PaH }\end{array}$ & $\begin{array}{c}\text { Shellfish } \\
\text { disease }\end{array}$ & $\begin{array}{c}\text { Samples } \\
\text { tested }\end{array}$ \\
\hline Albania & 2 & 733 & 30 & 355 & 35 & - & 1,153 \\
\hline Bosnia-Herzegovina & 2 & 140 & 42 & 66 & 10 & - & 258 \\
\hline Croatia & 82 & 15,506 & 403 & 8,722 & 665 & - & 25,296 \\
\hline Italy & 145 & 784 & 90 & 581 & 12 & 3 & 1,470 \\
\hline Montenegro & 6 & 715 & 72 & 424 & 90 & - & 1,301 \\
\hline Total & 237 & 17,878 & 637 & 10,148 & 812 & 3 & 29,478 \\
\hline
\end{tabular}

PaH, polycyclic aromatic hydrocarbons.

Table 3. Classification of production and relay areas in each country.

\begin{tabular}{|c|c|c|c|c|c|}
\hline Country & $\mathbf{A}$ & iific & C & $\begin{array}{l}\text { Areas without } \\
\text { sanitary classification* }\end{array}$ & $\begin{array}{c}\text { Number of areas } \\
\text { monitored }\end{array}$ \\
\hline Albania & 0 & 1 & 0 & 1 & 2 \\
\hline Bosnia-Herzegovina & 2 & 0 & 0 & 0 & 2 \\
\hline Croatia & 59 & 6 & 0 & 17 & 82 \\
\hline Italy & 58 & 12 & 0 & 75 & 145 \\
\hline Montenegro & 0 & 0 & 0 & 6 & 6 \\
\hline Total & 119 & 19 & 0 & 99 & 237 \\
\hline
\end{tabular}

A, areas from which molluscs may be collected for direct human consumption; B, areas from which molluscs may be collected but placed on the market for human consumption only after treatment in a purification centre or after relaying; C, areas from which molluscs may be collected but placed on the market only after relaying over a long period (at least two months) or after heat treatment by an approved method. ${ }^{*}$ To be updated over following years and according to new local regulations. 
from the database through the test result application. A list of received samples is provided in a table and the user can edit and updating the row showing the test results (Figure 7).

The area management and point management applications are available in the geographical unit section. For example, a new production area (Figure 8) and a new sampling point, respectively, can be entered there. The production area and the sampling point will then immediately be displayed on the map and in the table (alphanumerical attributes). This action can be performed by a system administrator or a CA user. Figure 9 highlights how to add a new classification to a production area. The system also keeps track of previous classifications (that are visible by opening the sub-table available for each row in the table). This action can only be performed by a CA user.

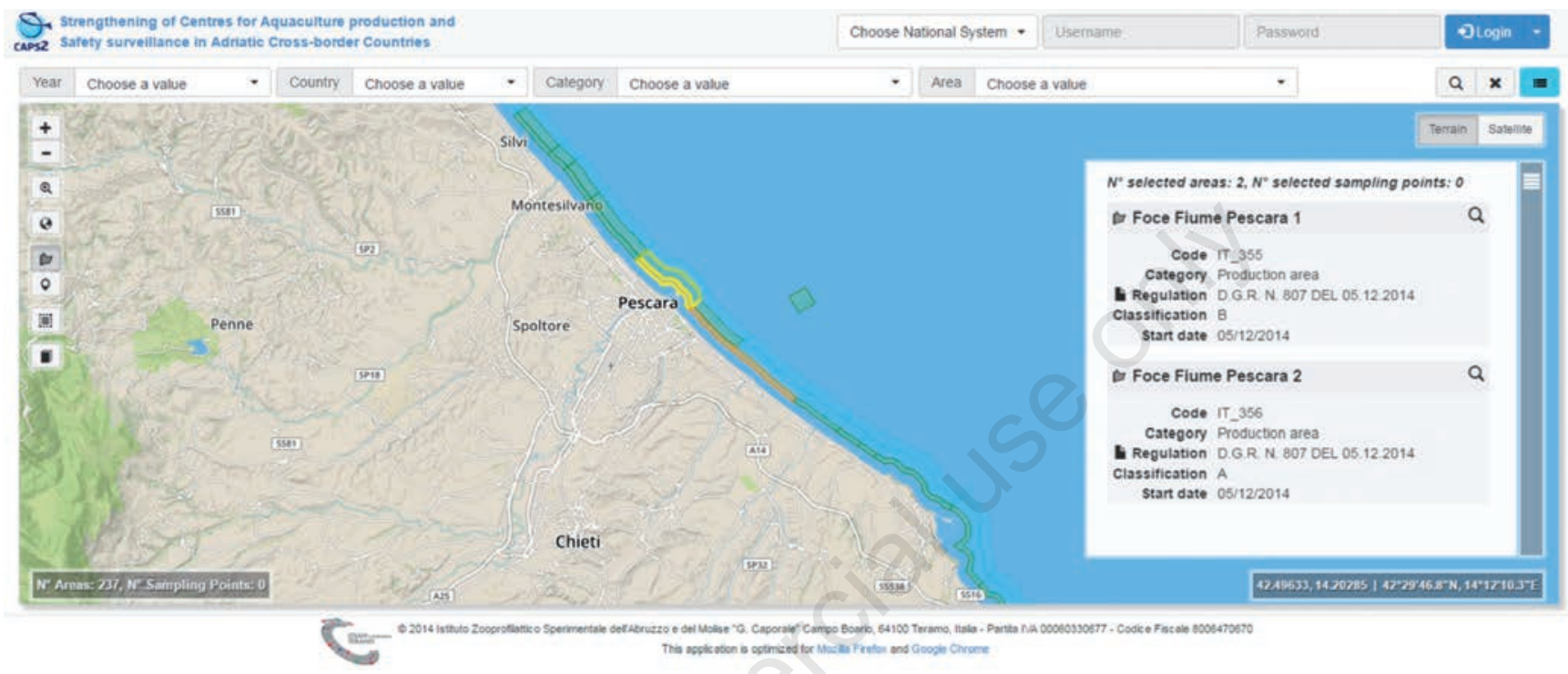

Figure 3. The supranational Web geographic information system application for the entire Adriatic area with classification details for Abruzzo and Molise regions.

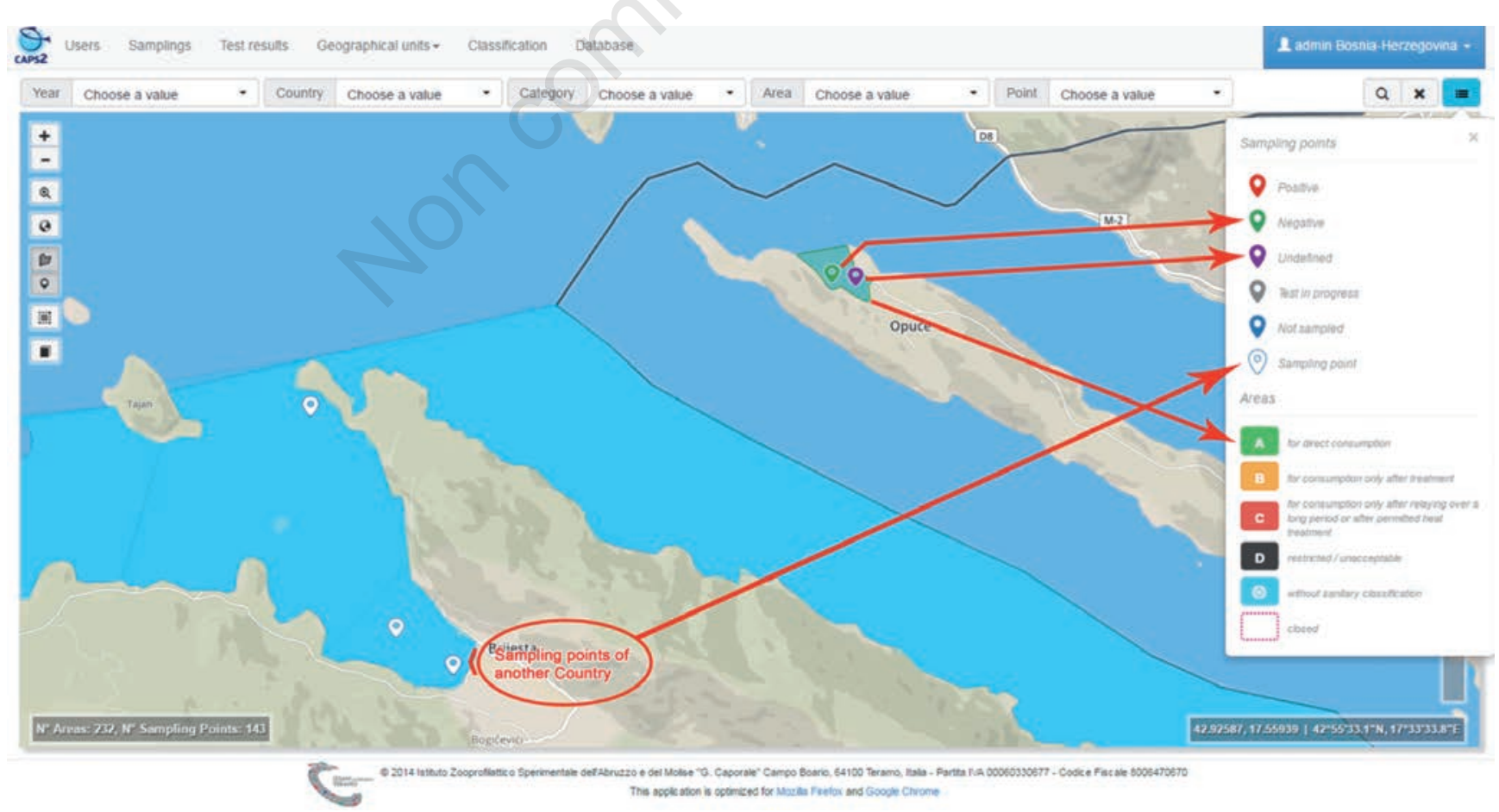

Figure 4. Data and relative legend available on the supranational Web geographic information system for an authorised user. The sampling points are coloured according to the outcome of samples analyses performed. 


\section{Discussion}

The EC regulation 854/2004 requires that the CAs in each European country clearly define production areas, microbiological quality and potential presence of toxin-producing plankton and/or chemical contaminants for bivalve molluses and establish surveillance systems to classify them accordingly. In case of non-compli- ance with the health standards, harvesting of the molluscs is prohibited or differently regulated. The consortium activities encouraged the development of national surveillance plans in partner countries to progressively achieve EU standards and to comply with the specification of EU directives. The CAPS2 information system was developed at the national and supranational levels to support the CAs in these activities. Although several web-based

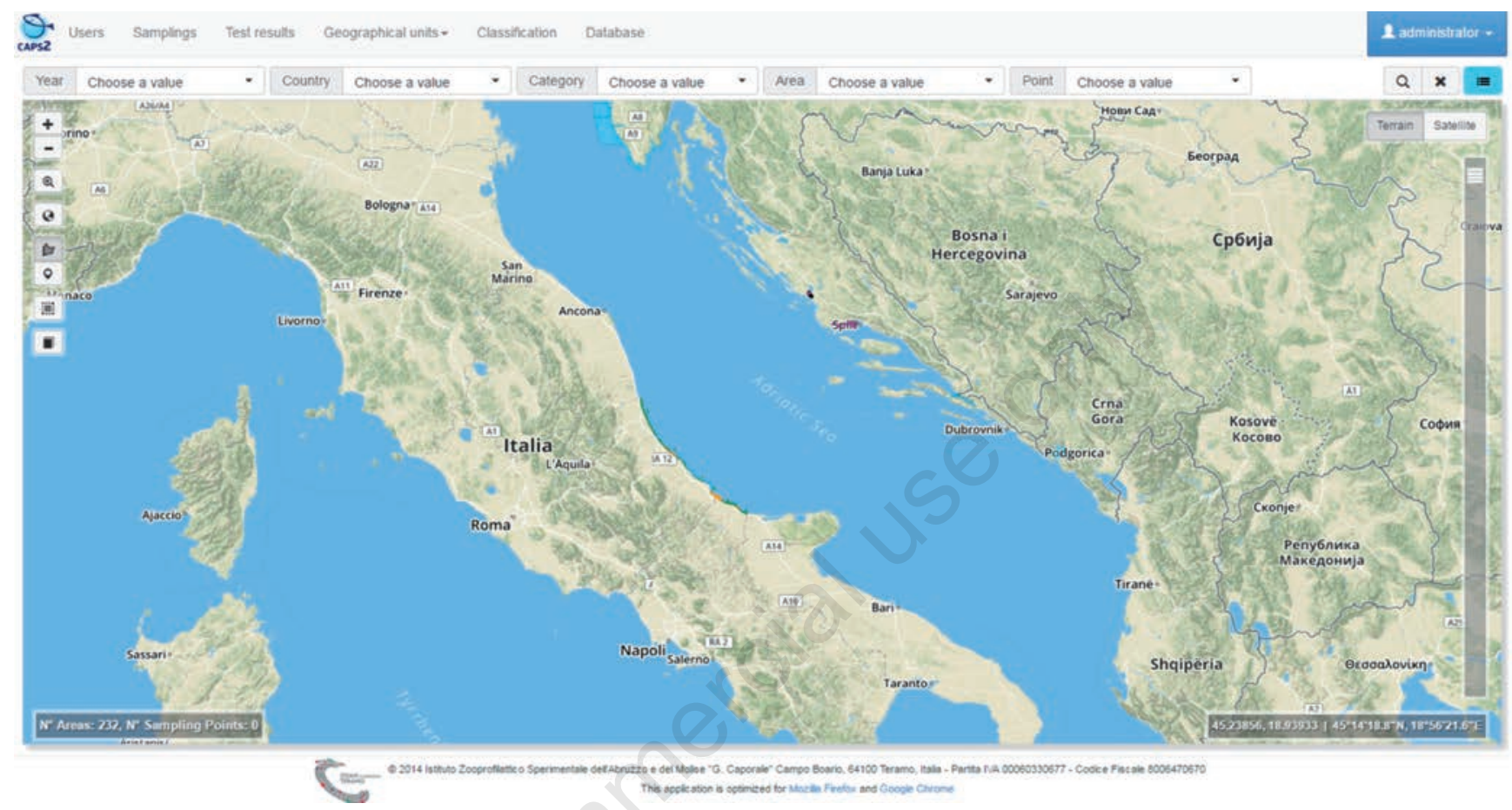

Figure 5. Screenshot showing access to CAPS2 geographic information system (national level) according to user profile. Available applications: user, sampling, test result, geographical unit, classification, database.

Samplings Test results

\section{Samplings management}

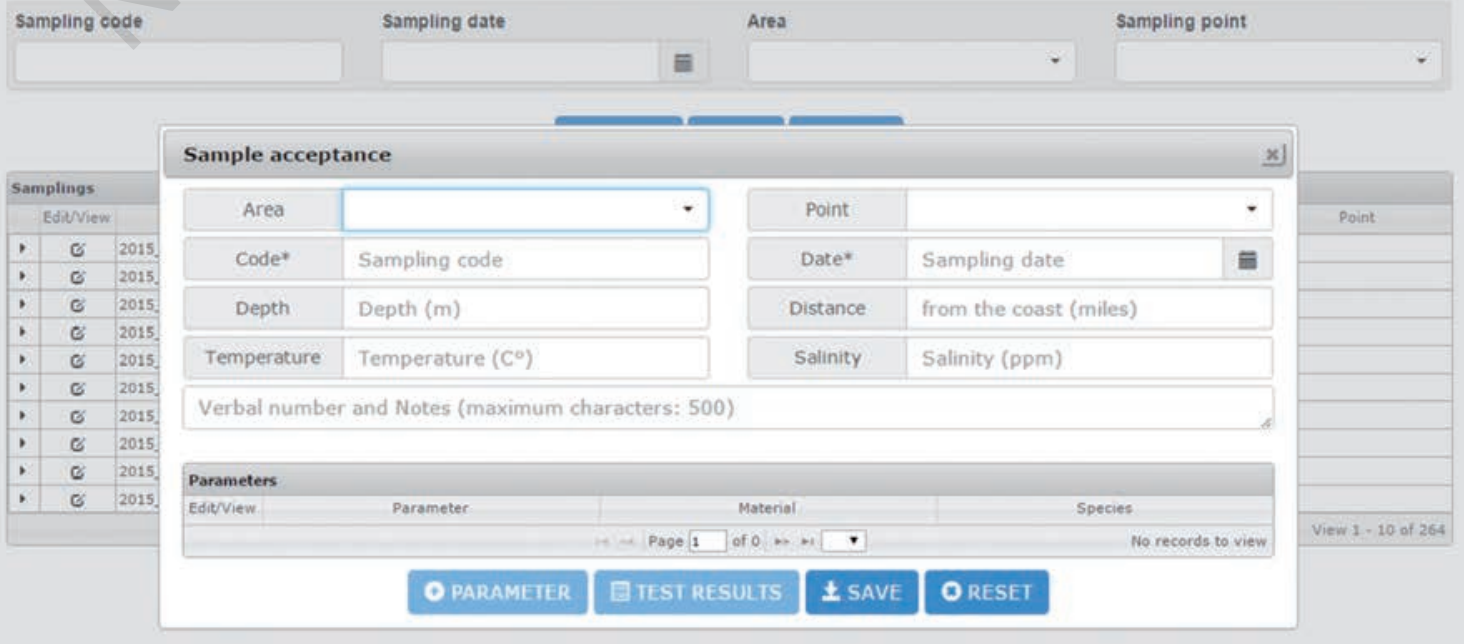

Figure 6. The sampling application. 


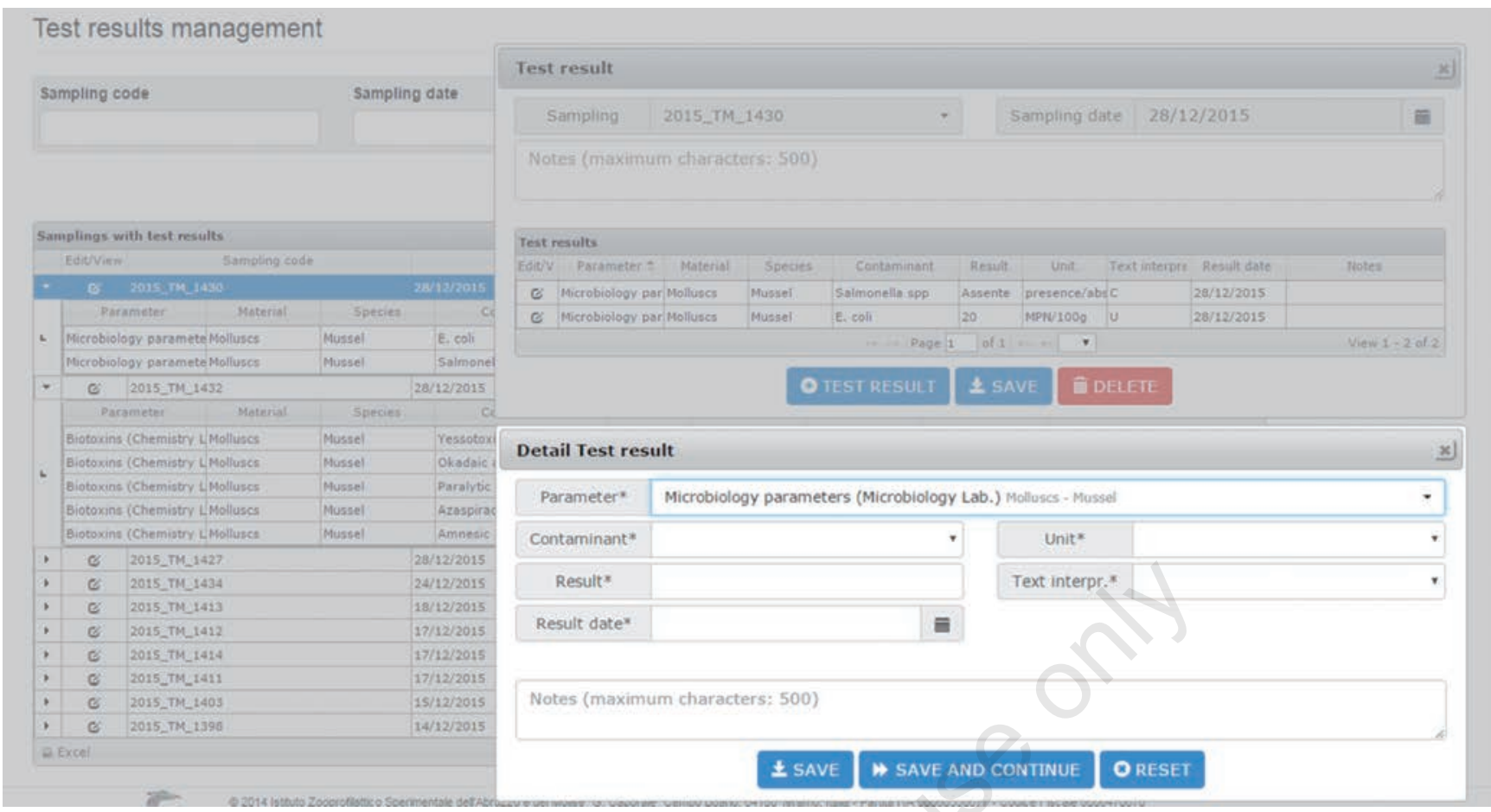

Figure 7. The test result application.

\section{Area management}

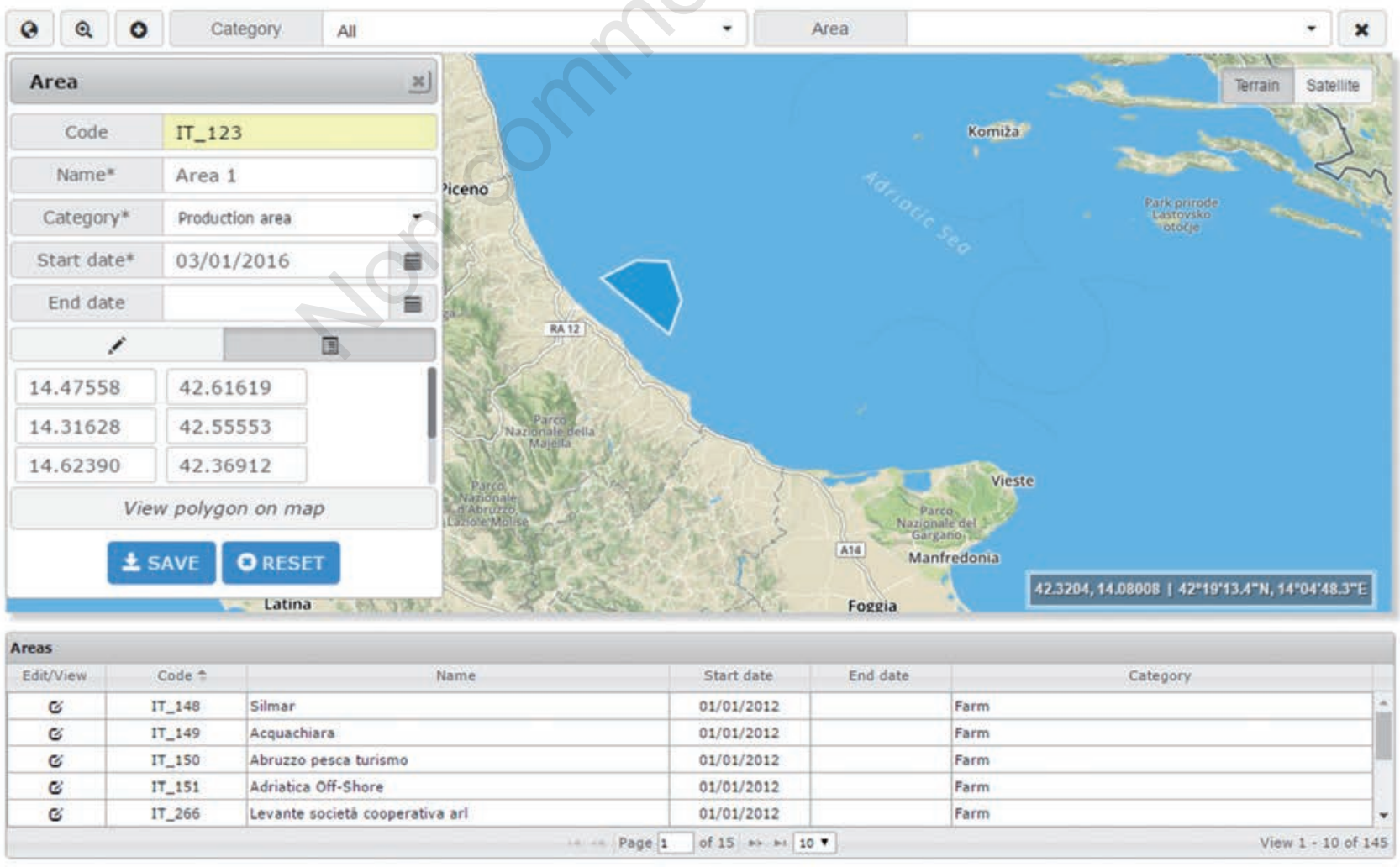

Figure 8. The geographical unit-area management application. 
applications have been developed for animal diseases at the national and international levels (Conte et al., 2005; Savini et al., 2006; Di Lorenzo et al., 2016), the CAPS2 is one of few examples of Web-based map services for bivalve molluscs containing GIS functionalities for surveillance activities that is available so far (Ferrè et al., 2011).

The system administration now considers about 50 different diagnostic tests (Appendix) in the framework of different surveillance plans implemented in countries making advanced tools in terms of maps and data manipulation available. The partner consortium discussed here relied on a large number of experts to evaluate and define the information needed to be implemented. Gathering and standardising the information coming from the different surveillance plans and integrate data into a common, single system represents one of the most challenging aspects of the work.

The considerable amount of data uploaded in the system in a year (release date of January 2016) is an indicator of the need that Adriatic countries have in terms of distributing and sharing information. The system described is an accurate and complex engineering process that starts with a careful analysis of needs and information to be collected and ends up with the application of a completely new approach. Its development required considerable costs in terms of human and financial resources to train people, recruit and retain technical expertise, acquire the necessary hardware and software for data analysis and improve network services via the Internet. Its maintenance requires additional economic input to update data and support the administration. Costly though any Web-based GIS may be, the flexibility of these tools (ranging from the simplest to the most advanced and customised software) makes it possible to develop applications suitable to any geographical context and to any disease where spatial components play an important role.

\section{Conclusions}

The collection of relevant epidemiological data is fundamental for any scientific assessment of the risks of pathogen introduction and/or food safety risk assessment. Information generated by the CAPS2 GIS and distributed via the Internet provides a precious resource facilitating decision-making processes and management of control activities both at central and local levels, which is of benefit to all stakeholders. The integrated Web GIS, including both qualitative and quantitative data, enhances evaluation and adoption of health policies, simplifies cost/benefit analysis greatly and enlarges the different control options by authorities in charge. In this context, the next step will be the development of an integrated risk assessment of the whole area in agreement with all participating countries.

\section{Sanitary classification}

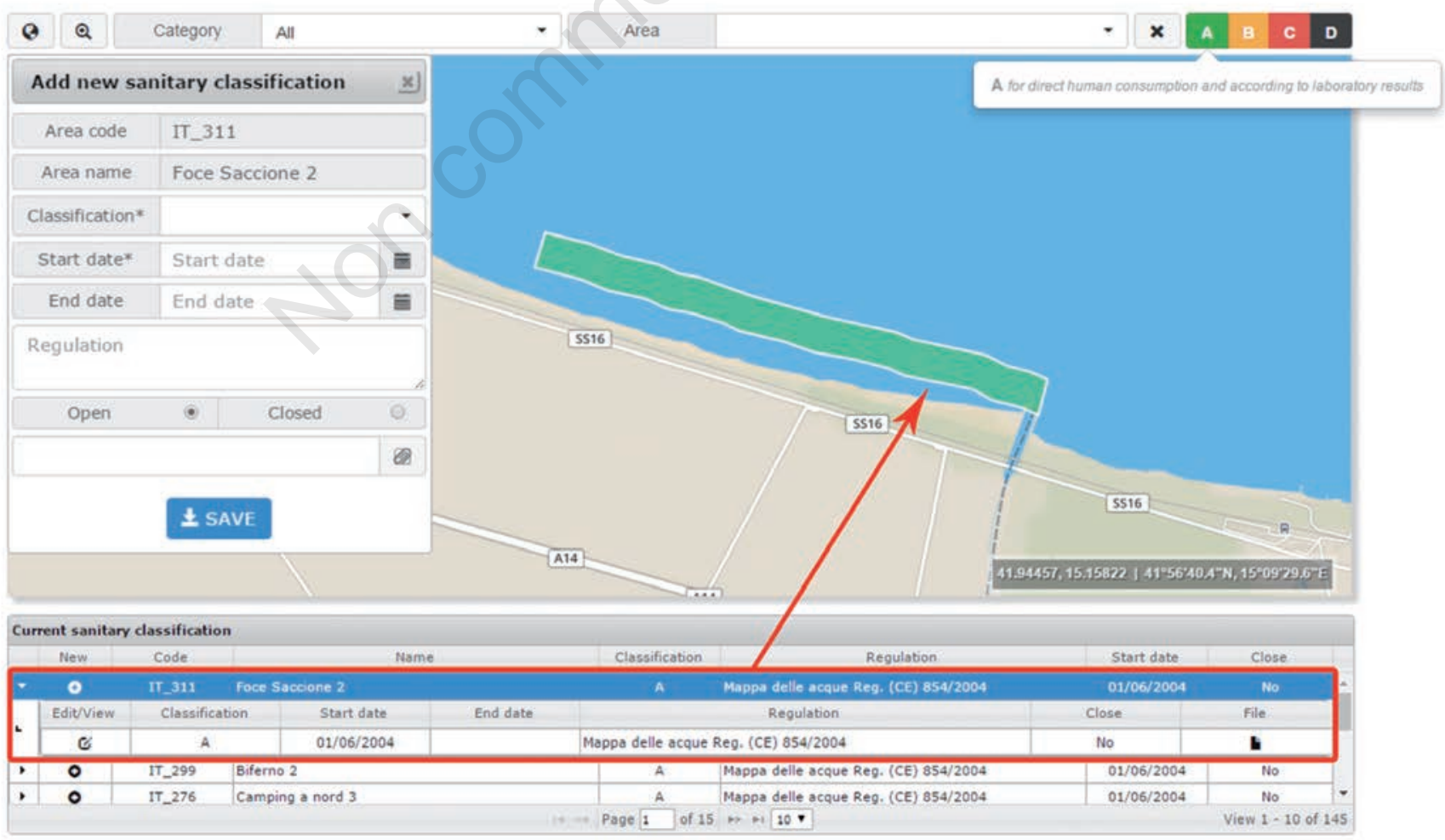

Figure 9. The data entry module for classification. 


\section{References}

Bogdanović T, Ujević, I, Sedak M, Listeš E, Šimat V, Petričević S, Poljak V, 2014. As, $\mathrm{Cd}, \mathrm{Hg}$ and $\mathrm{Pb}$ in four edible shellfish species from breeding and harvesting areas along the eastern Adriatic Coast, Croatia. Food Chem 146:197-203.

Conte A, Colangeli P, Ippoliti C, Paladini C, Ambrosini M, Savini L, Dall'Acqua F, Calistri P, 2005. The use of a web-based interactive geographical information system for the surveillance of bluetongue in Italy. Rev Sci Tech Int Off Epizoot 24:857-68.

Di Lorenzo A, Di Sabatino D, Cioci D, Conte A, Bruno R, Sauro F, Calistri P, Savini L, 2016. The Arbo-zoonet Information System. Vet Ital 52:161-8.

EPCEU, 2004a. Regulation of the European Parliament and of the Council of 29 April 2004 laying down specific hygiene rules for food of animal origin, 853/2004/EC. In: Official Journal, L $139 / 55,30.4 .2004$.

EPCEU, 2004b. Regulation of the European Parliament and of the Council of 29 April 2004 laying down specific rules for the organisation of official controls on products of animal origin intended for human consumption, 854/2004/EC. In: Official Journal, L 155/206, 30.4.2004.

EPCEU, 2008. Directive of the European Parliament and of the Council of 17 June 2008 establishing a framework for community action in the field of marine environmental policy (Marine Strategy Framework Directive), 2008/56/EC. In: Official Journal, L 164/19, 25.6.2008.

European Commission, 2006. Commission Regulation of 19 December 2006 setting maximum levels for certain contami- nants in foodstuffs, 1881/2006/EC. In: Official Journal, L 364/5, 20.12.2006.

European Commission, 2011. Commission Regulation of 19 August 2011 amending Regulation (EC) No 1881/2006 as regards maximum levels for polycyclic aromatic hydrocarbons in foodstuffs, 835/2011/EU. In: Official Journal, L 215/4, 20.8.2011.

European Commission, 2013. Commission Regulation of 16 August 2013 amending Annex III to Regulation (EC) No $853 / 2004$ of the European Parliament and of the Council as regards the permitted limits of yessotoxins in live bivalve molluscs, 786/2013/EU. In: Official Journal, L 220/14, 17-8-13.

Ferrè N, Mulatti $P$, Mazzucato $M$, Lorenzetto $M$, Trolese $M$, Pandolfo D, Vio P, Sitta G, Marangon S, 2011. GeoCREV: veterinary geographical information system and the development of a practical sub-national spatial data infrastructure. Geospat Health 5:275-83.

Grigorakis K, 2007. Compositional and organoleptic quality of farmed and wild gilthead sea bream (Sparus aurata) and sea bass (Dicentrarchus labrax) and factors affecting it: A review. Aquaculture 272:1-4;55-75.

Savini L, Ippoliti C, Conte A, Parisse M, Dall'Acqua F, Calistri P, 2006. Development of a web-based geographic information system for the epidemiological surveillance of bluetongue in the Balkans and eastern Mediterranean countries. Vet Ital 42:201-7;193-9.

Ujević I, Vuletić N, Lušić J, Nazlić N, Kušpilić G, 2015. Bioaccumulation of trace metals in mussel (Mytilus galloprovincialis) from Mali Ston Bay during DSP toxicity episodes. Molecules 20:13031-40. 